\title{
Originals
}

\section{Haemostatic Changes in Diabetic Coma}

\author{
R. C. Paton \\ Department of Medicine, University of Aberdeen, UK
}

Summary. Diabetic coma is frequently associated with thromboembolic complications. A prospective study was undertaken of the haemostatic changes occurring in 15 patients ( 12 with ketoacidosis, three with the hyperosmolar syndrome) during diabetic coma. When compared with the results after stabilization of the diabetes, ketoacidosis was associated with significantly higher levels of factor VIII coagulant activity, factor VIII-related antigen and fibrin degradation products, a shorter partial thromboplastin time and reduced concentrations of antithrombin III. These results suggest that in uncomplicated ketoacidosis, haematological changes occur which may reflect vascular endothelial damage and intravascular fibrin deposition. Out of three deaths, two patients (both with the hyperosmolar syndrome) had evidence of disseminated intravascular coagulation. To reduce further the mortality and morbidity from diabetic coma, controlled clinical trials of anticoagulant and antiplatelet drugs may be indicated.

Key words: Diabetic coma, factor VIII, disseminated intravascular coagulation.

Many abnormalities of haemostatic function have been described in diabetes mellitus. These include increased platelet retention and aggregation [1], increased levels of coagulation factors [2] and diminished fibrinolytic activity [3]. Whether these abnormalities are related to the metabolic disturbances of diabetes is unclear.

Whatever the relationship between metabolic control and haemostatic dysfunction, it is increasingly realized that thromboembolic disease is a frequent complication of diabetic coma. Arterial thrombosis may be responsible for up to one-third of deaths in patients with diabetic ketoacidosis [4], and is a frequent occurrence in non-ketotic hyperosmolar coma [5]. In addition, Timperley et al. have shown that localized deposition of fibrin may occur in fatal cases of ketoacidosis, particularly in the cerebral capillaries [6]. Over the past decade, a number of authors have described the association of disseminated intravascular coagulation and diabetic coma [6-8]. However, such case reports have been sporadic, and laboratory studies have generally been undertaken only after clinical signs were apparent. A prospective study was therefore designed to determine the nature of haemostatic changes in unselected cases of diabetic ketoacidosis and the non-ketotic hyperosmolar syndrome.

\section{Subjects and Methods}

\section{Patients}

Fifteen diabetic patients, admitted to the Aberdeen Teaching Hospitals with ketoacidosis or the hyperosmolar syndrome over a period of 12 months, were included in the study. Diabetic ketoacidosis was arbitrarily defined as a plasma glucose $>14 \mathrm{mmol} / 1$ and a serum bicarbonate of $11 \mathrm{mmol} / \mathrm{l}$ or less in association with ketonuria. The non-ketotic hyperosmolar syndrome was defined as a plasma glucose $>30 \mathrm{mmol} / 1$ with a serum osmolarity of $>350 \mathrm{mOsmol} / 1$ [9], serum bicarbonate $>20 \mathrm{mmol} / 1$ and with no more than a trace of ketonuria.

Where possible, a second, "convalescent" sample was obtained from the patients at a subsequent outpatient visit when the diabetic state was stable (non-fasting plasma glucose $<10 \mathrm{mmol} / \mathrm{l}$ and $\mathrm{ab}-$ sence of ketonuria).

\section{Methods}

Venous blood was removed from the patients as soon as possible after arrival at hospital (mean $2.2 \mathrm{~h}$, range $0.1-5 \mathrm{~h}$ ) for biochemical and haematological studies. Blood for assays of the coagulation 
Table 1. Clinical details of patients with diabetic coma

\begin{tabular}{|c|c|c|c|c|c|c|c|c|}
\hline $\begin{array}{l}\text { Patient } \\
\text { no. }\end{array}$ & Sex & $\begin{array}{l}\text { Age } \\
\text { (years) }\end{array}$ & $\begin{array}{l}\text { Duration } \\
\text { of diabetes } \\
\text { (years) }\end{array}$ & $\begin{array}{l}\text { Previous } \\
\text { diabetic } \\
\text { treatment }\end{array}$ & $\begin{array}{l}\text { Possible } \\
\text { precipitating } \\
\text { factors }\end{array}$ & $\begin{array}{l}\text { Additional } \\
\text { drugs }\end{array}$ & $\begin{array}{l}\text { Depth of } \\
\text { coma }\end{array}$ & Outcome \\
\hline 1 & M & 18 & 4 & insulin & tonsillitis & erythromycin & 3 & recovery \\
\hline 2 & $\mathrm{~F}$ & 52 & new & none & breast abcess & $\begin{array}{l}\text { amoxycillin, } \\
\text { bendrofluazide } \mathbf{K}^{+}\end{array}$ & 1 & recovery \\
\hline 3 & $\mathrm{~F}$ & 65 & 46 & insulin & unknown & - & 4 & death \\
\hline 4 & $\mathrm{~F}$ & 21 & 10 & insulin & unstable diabetes & - & 3 & recovery \\
\hline 5 & $\mathbf{M}$ & 17 & new & none & unknown & - & 4 & recovery \\
\hline 6 & $\mathrm{~F}$ & 15 & 6 & insulin & unstable diabetes & - & 2 & recovery \\
\hline 7 & $\mathrm{~F}$ & 13 & 1 & insulin & dental abcess & - & 2 & recovery \\
\hline 8 & M & 33 & 13 & insulin & ischiorectal abcess & - & 2 & recovery \\
\hline 9 & $\mathrm{~F}$ & 16 & 1 & insulin & unstable diabetes & - & 2 & recovery \\
\hline 10 & $\mathbf{M}$ & 17 & new & insulin & stopped insulin & - & 3 & recovery \\
\hline 11 & $\mathrm{~F}$ & 33 & new & none & unknown & - & 2 & recovery \\
\hline 12 & M & 42 & 16 & insulin & unknown & - & 3 & recovery \\
\hline 13 & $\mathbf{M}$ & 65 & new & none & unknown & - & 3 & recovery \\
\hline 14 & M & 73 & new & none & unknown & $\begin{array}{l}\text { frusemide, digoxin, } \\
\text { inositol nicotinate }\end{array}$ & 3 & death \\
\hline 15 & F & 81 & 17 & chlorpropamide & stopped sulphonylurea & - & 3 & death \\
\hline
\end{tabular}

Table 2. Biochemical data of patients with diabetic coma

\begin{tabular}{|c|c|c|c|c|c|c|c|}
\hline $\begin{array}{l}\text { Patient } \\
\text { no. }\end{array}$ & $\begin{array}{l}\text { Plasma } \\
\text { glucose } \\
(\mathrm{mmol} / \mathrm{l})\end{array}$ & $\begin{array}{l}\text { Serum } \\
\text { urea } \\
(\mathrm{mmol} / \mathrm{l})\end{array}$ & $\begin{array}{l}\text { Serum } \\
\text { sodium } \\
(\mathrm{mmol} / \mathrm{l})\end{array}$ & $\begin{array}{l}\text { Serum } \\
\text { potassium } \\
(\mathrm{mmol} / \mathrm{l})\end{array}$ & $\begin{array}{l}\text { Serum } \\
\text { bicarbonate } \\
(\mathrm{mmol} / \mathrm{l})\end{array}$ & $\begin{array}{l}\text { Serum } \\
\text { osmolarity } \\
(\mathrm{mOsmol} / \mathrm{l})\end{array}$ & $\begin{array}{l}\text { Urinary } \\
\text { ketones }\end{array}$ \\
\hline 1 & 32.4 & 9.4 & 128 & 5.4 & 5 & 309 & +++ \\
\hline 2 & 21.4 & 8.0 & 151 & 2.4 & 8 & 336 & +++ \\
\hline 3 & 54.9 & 14.7 & 132 & 7.2 & 5 & 348 & +++ \\
\hline 4 & 14.2 & 5.5 & 153 & 6.5 & 5 & 339 & +++ \\
\hline 5 & 78.5 & 38.0 & 146 & 4.4 & 11 & 417 & +++ \\
\hline 6 & 39.3 & 6.8 & 136 & 5.5 & 5 & 329 & +++ \\
\hline 7 & 25.0 & 4.0 & 133 & 3.7 & 5 & 302 & +++ \\
\hline 8 & 34.6 & 8.3 & 134 & 6.6 & 5 & 324 & +++ \\
\hline 9 & 17.1 & 8.2 & 142 & 4.6 & 11 & 318 & ++ \\
\hline 10 & 20.9 & 5.6 & 136 & 3.5 & 5 & 305 & +++ \\
\hline 11 & 42.9 & 7.0 & 138 & 2.5 & 5 & 331 & +++ \\
\hline 12 & 69.0 & 39.0 & 143 & 6.5 & 11 & 407 & ++ \\
\hline 13 & 31.1 & 18.2 & 161 & 4.1 & 24 & 380 & - \\
\hline 14 & 56.1 & 35.2 & 145 & 5.7 & 22 & 393 & trace \\
\hline 15 & 48.4 & 28.1 & 163 & 4.0 & 24 & 410 & - \\
\hline
\end{tabular}

system was immediately placed on ice and centrifuged at $1500 \times g$ and $4{ }^{\circ} \mathrm{C}$ within $30 \mathrm{~min}$ of venepuncture. Prothrombin and partial thromboplastin times were measured on fresh samples and the remaining plasma stored at $-70^{\circ} \mathrm{C}$ until required.

The whole blood platelet count was measured microscopically [10]. Partial thromboplastin time was measured by the method of Langdell et al. [11] and the prothrombin time by the method of Quick [12]. Factor V and factor VIII coagulant activity (VIII: C) were assayed by one-stage techniques based on the correction of the prolonged clotting times of specific factor deficient plasmas $[13,14]$. Factor VIII-related antigen (VIII R: Ag) was measured by immuno-electrophoresis using antibody to factor VIIIR: Ag produced by Behringwerke (Marburg, FRG) [15]. A normal pool of plasma obtained from 20 healthy male medical students was used as a control. Plasma antithrombin III was measured by a radial diffusion technique, using plates and standards supplied by Behringwerke. Plasma fibrinogen was measured by a modification
[16] of the method of Ratnoff and Menzie, and plasma plasminogen by the method of Alkjaersig et al. [17]. Fibrin degradation products were measured using the kit supplied by Wellcome Reagents (Beckenham, Kent, UK) Packed cell volume was estimated using a microhaematocrit centrifuge (Hawksley \& Sons, Lancing, Sussex, UK). Since dehydration occurs during diabetic coma, concentrations of haemostatic factors were adjusted for changes in haematocrit [18]: Corrected concentration = measured concen-

tration $\times \frac{\mathrm{H}_{1}\left(100-\mathrm{H}_{2}\right)}{\mathrm{H}_{2}\left(100-\mathrm{H}_{1}\right)}$

Where: $\mathrm{H}_{1}=$ haematocrit after coma

$\mathrm{H}_{2}=$ haematocrit during coma

This formula is based on the assumption that the red cell mass remains relatively constant during diabetic coma, and that changes in haematocrit reflect changes in plasma volume. Results are pre- 
Table 3. Mean \pm SEM values of haemostatic factors of 11 diabetics during ketoacidosis, ketoacidosis with the values corrected for dehydration and during convalescence

\begin{tabular}{|c|c|c|c|c|}
\hline Test & $\begin{array}{l}\text { Ketoacidosis } \\
\text { (measured values) }\end{array}$ & $\begin{array}{l}\text { Ketoacidosis } \\
\text { (corrected values) }\end{array}$ & Convalescence & Normal controls ${ }^{a}$ \\
\hline Haematocrit $(\%)$ & $45.6 \pm 1.8^{\mathrm{d}}$ & & $40.7 \pm 1.5$ & \\
\hline Prothrombin time (ratio) & $1.00 \pm 0.03$ & & $0.96 \pm 0.04$ & \\
\hline Partial thromboplastin time (ratio) & $0.90 \pm 0.04^{\mathrm{c}}$ & & $0.99 \pm 0.03$ & \\
\hline Platelef count $\left(\times 10^{9} / 1\right)$ & $406 \pm 43^{c}$ & $331 \pm 31$ & $299 \pm 17$ & \\
\hline Factor $V(\%)$ & $110 \pm 10$ & $90 \pm 9$ & $118 \pm 15$ & \\
\hline Factor VIII: C (\%) & $350 \pm 36^{b}$ & $278 \pm 33^{d}$ & $189 \pm 23$ & \\
\hline Factor VIIIR: Ag (\%) & $535 \pm 156^{b}$ & $511 \pm 226^{\mathrm{b}}$ & $125 \pm 10$ & \\
\hline Fibrinogen $(g / 1)$ & $6.35 \pm 0.63$ & $5.63 \pm 1.02$ & $5.19 \pm 0.32$ & $3.92 \pm 1.35$ \\
\hline Plasminogen (casein $\mathrm{U} / \mathrm{ml}$ ) & $4.19 \pm 0.16$ & $3.51 \pm 0.29^{d}$ & $4.09 \pm 0.17$ & $3.56 \pm 0.07$ \\
\hline Antithrombin III (mg/dl) & $32.2 \pm 1.4^{b}$ & $26.4 \pm 1.0^{\mathrm{b}}$ & $36.3 \pm 0.3$ & $46.5 \pm 1.0$ \\
\hline Fibrin degradation products $(\mu \mathrm{g} / \mathrm{ml})$ & $17.7 \pm 4.5^{\mathrm{d}}$ & $15.4 \pm 4.4$ & $8.7 \pm 0.9$ & $<5$ \\
\hline
\end{tabular}

a Mean \pm SEM values for 34 healthy non-diabetic subjects.

b $p<0.01,{ }^{c} p<0.02,{ }^{d} p<0.05$ compared with convalescent values

Table 4. Haemostatic tests of the fatal case of ketoacidosis (patient 3) and the three diabetics with the hyperosmolar syndrome (patients 13, $14,15)$

\begin{tabular}{|c|c|c|c|c|c|}
\hline Test & Patient 3 & Patient 13 & Patient 14 & Patient 15 & Normal control $^{\mathrm{a}}$ \\
\hline Haematocrit $(\%)$ & 40 & 40 & 49 & 39 & \\
\hline Prothrombin time (ratio) & 1.01 & 1.01 & 1.41 & 0.88 & \\
\hline Partial thromboplastin time (ratio) & 1.33 & 0.60 & 0.98 & 0.83 & \\
\hline Platelet count $\left(\times 10^{9} / 1\right)$ & 540 & 311 & 82 & 184 & \\
\hline Factor $\mathrm{V}(\%)$ & 104 & 102 & 42 & 104 & \\
\hline Factor VIII: C (\%) & 240 & 570 & 184 & 760 & \\
\hline Factor VIIR: $\mathrm{Ag}(\%)$ & 248 & 280 & 352 & 1200 & \\
\hline Fibrinogen $(\mathrm{g} / \mathrm{l})$ & 5.20 & 10.15 & 10.32 & 4.25 & $3.92 \pm 1.35$ \\
\hline Plasminogen (casein $\mathrm{U} / \mathrm{ml}$ ) & 3.31 & 4.34 & 2.75 & 1.76 & $3.56 \pm 0.07$ \\
\hline Antithrombin III $(\mathrm{mg} / \mathrm{dl})$ & 27.2 & 27.2 & 26.0 & 27.7 & $46.5 \pm 1.0$ \\
\hline Fibrin degradation products $(\mu \mathrm{g} / \mathrm{ml})$ & 20 & 10 & 160 & 80 & $<5$ \\
\hline
\end{tabular}

a Mean \pm SEM values for 34 healthy non-diabetic subjects

sented both as measured and corrected concentrations. Plasma glucose was measured by the glucose oxidase method and serum urea and electrolytes by autoanalyzer. Urinary ketones were measured by Ketostix (Ames). Serum osmolarity was calculated using the formula of Gordon and Kabadi [9], and depth of coma on admission was assessed clinically, using a score of 1-4 $(1=$ normal, 2 = drowsy, but responding to verbal commands, $3=$ responding only to painful stimuli, $4=$ unrousable).

\section{Statistics}

Comparison between results during and after diabetic coma was made using the Wilcoxon rank sign test for paired samples.

\section{Results}

\section{Patients}

Fifteen diabetics were admitted to the study. Clinical details are shown in Table 1 and biochemical data in Table 2. Findings in the 12 patients with ketoacidosis are discussed separately from the three patients with the hyperosmolar syndrome.

\section{Patients with Ketoacidosis}

Patient 3 died $3 \mathrm{~h}$ after admission following a cardiac arrest. The results of the haemostatic tests of the surviving 11 patients are summarized in Table 3 . The normal values for fibrinogen, plasminogen, antithrombin III and fibrin degradation products shown in Tables 3 and 4 were obtained from 34 healthy non-diabetic controls ( 22 men, 12 women) with a mean age of 39.1 years (range 26-65 years). Compared with convalescent values, platelet count, factor VIII: C, VIIIR: Ag and fibrin degradation products were significantly increased. Antithrombin III concentrations were significantly lower and there was a significant shortening of the partial thromboplastin time during ketoacidosis. 
When the results were corrected for the effect of dehydration, factor VIII: C and VIIIR: Ag were still significantly higher and antithrombin III concentrations lower, during ketoacidosis. The differences in platelet count and fibrin degradation products were no longer significant, though seven out of the 11 patients had corrected concentrations of fibrin degradation products greater than $10 \mu \mathrm{g} / \mathrm{ml}$ compared with only one out of 11 convalescent samples. In addition, corrected mean plasminogen concentrations were significantly lower during ketoacidosis. The mean ( \pm SEM) factor VIIIR: Ag/VIII: C ratio was $1.44 \pm$ 0.27 during ketoacidosis, which was significantly higher than the convalescent value of $0.73 \pm 0.08$ $(p<0.01)$. There was no correlation between the levels of the various haemostatic factors and the depth of coma, the presence of overt infection, plasma glucose, serum bicarbonate and the serum osmolarity. Neither the two patients with severe hypokalaemia (patients 2 and 11) nor the two with a blood urea greater than $30 \mathrm{mmol} / \mathrm{l}$ (patients 5 and 12) had haemostatic values strikingly different from the remaining ketoacidotic patients.

\section{Patients with the Hyperosmolar Syndrome}

Out of the three diabetics with the hyperosmolar syndrome, two died (patients 14 and 15). The haemostatic results on admission are shown in Table 4, together with the fatal case with ketoacidosis (patient 3 ). Results are reported as uncorrected values. Patients 3 and 13 showed results similar to the surviving patients with ketoacidosis shown in Table 3. In contrast, the two fatal hyperosmolar cases (patients 14 and 15) had thrombocytopenia, low concentrations of plasminogen and raised levels of fibrin degradation products.

Patient 14 had a past history of ischaemic heart disease and intermittent claudication. On admission, he was found to have impalpable pulses from the left femoral downwards. The hyperosmolar state was rapidly corrected with fluid and insulin therapy, but perfusion of the left leg did not improve, below-knee amputation being required six days later, followed by death after a further eight days. The severe thrombocytopenia present on admission persisted throughout his final illness. Post-mortem was not performed.

Patient 15 was admitted in hyperosmolar coma. On examination she had minimal abdominal tenderness and absent bowel sounds. Death occurred $12 \mathrm{~h}$ after admission. At autopsy she was found to have $80 \mathrm{~cm}$ of infarcted small intestine and when sections were stained with Martius yellow, Crystal scarlet and soluble blue, fibrin was observed in capillaries, venules and arterioles of lungs, mesentry, renal glomeruli and cerebral cortex.

\section{Discussion}

This study shows that characteristic changes occur in the haemostatic system during diabetic ketoacidosis, the most striking abnormality being a rise in factor VIII: C and VIIIR: Ag. Increased levels of the factor VIII complex are found in a variety of inflammatory, thromboembolic and neoplastic conditions [19]. On the other hand, high factor VIII: $\mathrm{C}$ and particularly VIIIR: Ag concentrations have frequently been observed in stable diabetics $[20,21]$. Recent evidence suggests that factor VIII Ristocetin cofactor activity (which tends to parallel the VIIIR: Ag level) can be reduced by strict metabolic control of the diabetes [22]. The present study lends additional support to the view that poor diabetic control produces raised factor VIII levels. Since factor VIII R: Ag is synthetized by vascular endothelial cells [23], the high concentrations of this antigen found in diabetics with ketoacidosis may indicate the degree of insult sustained by the endothelium. Exposure of the vascular subendothelium is the first stage in the initiation of thrombus formation [24], so that endothelial cell damage with resulting de-endothelialization could be a major contributing factor to the high incidence of arterial thrombosis in fatal cases of diabetic ketoacidosis [4].

The cause of raised factor VIII: $\mathrm{C}$ activity during ketoacidosis is not known, but could be a nonspecific response to acute stress [19]. Though raised levels of individual coagulation factors do not necessarily lead to an increased tendency to thrombosis [25], the finding of a significantly shortened partial thromboplastin time during ketoacidosis suggests that there is an increased activity of the intrinsic coagulation system, which might be expected to favour intravascular clotting. A slight, but significant, rise in the ratio of factor VIIIR: Ag/VIII: C was observed during ketoacidosis. Denson has shown that a proportionate decrease in factor VIII: $\mathrm{C}$ in relation to VIIIR: $\mathrm{Ag}$ can indicate intravascular coagulation [26]. However, since factor VIII: C activity is relatively labile, the possibility that coagulant activity was lost during blood collection or storage of the plasma cannot be excluded.

A fall in the concentration of antithrombin III appears to be an early and sensitive indicator of intravascular coagulation [27]. In the present study, a significant fall in antithrombin III together with a modest rise in fibrin degradation products provides evidence that even in relatively uncomplicated cases of ketoacidosis, a degree of fibrin generation occurs, and could contribute to the cerebral dysfunction often seen in this condition [6]. No correlation was found between the magnitude of the individual 
haemostatic factor abnormalities and clinical and biochemical variables such as presence of overt infection, depth of coma, extent of hyperglycaemia, osmolarity or uraemia. Since levels of both haemostatic and metabolic factors can change rapidly, future studies with more frequent blood sampling during recovery from ketoacidosis are required for clearer understanding of the relationships between clinical, metabolic and haemostatic parameters.

Two of the three patients with the hyperosmolar syndrome died during their admission to hospital. Both deaths occurred in elderly patients and illustrated the considerably higher mortality rate due to the hyperosmolar syndrome compared with that from ketoacidosis [9]. Both patients had laboratory, and in one case, pathological evidence of disseminated intravascular coagulation. The majority of patients with disseminated intravascular coagulation have reduced levels of fibrinogen and plasminogen, thrombocytopenia and diminished factor $\mathrm{V}$ and VIII: C with high levels of fibrin degradation products $[27,28]$. These haematological findings do not clearly distinguish disseminated intravascular coagulation from massive thrombosis at a single site, as was found in patient 14. Nevertheless, the persistent thrombocytopenia found in this patient is suggestive of platelet consumption in sites additional to the occluded femoral artery.

As shown in the present study, coagulation factor levels are frequently raised during uncomplicated diabetic coma, making any changes induced by disseminated intravascular coagulation difficult to interpret. Thus in previous reports of disseminated intravascular coagulation associated with diabetic coma, fibrinogen and factors V and VIII: $\mathrm{C}$ were high, low or normal [6-8], in agreement with the two cases in the present series. Thrombocytopaenia and raised fibrin degradation products appear to be more consistent findings. In addition, a low plasma plasminogen concentration may point to the diagnosis.

The aetiology of disseminated intravascular coagulation during diabetic coma is likely to be multiple. Infection [27, 28] and hypovolaemia [28] are known precipitating factors. Metabolic abnormalities may also play a part since disseminated intravascular coagulation is more readily induced in alloxantreated compared with control rats [29]. The use of sensitive radioimmunoassays such as those for fibrinopeptide $\mathrm{A}$, beta-thromboglobulin and platelet factor 4 may provide information on the relative contributions of the coagulation system, platelets and endothelium to the pathogenesis of intravascular coagulation during diabetic coma.

In summary, this study shows that during diabetic ketoacidosis, haemostatic changes are found which may reflect endothelial damage and also suggest intravascular fibrin deposition. In two fatal cases of the hyperosmolar syndrome, evidence of disseminated intravascular coagulation was found. In view of the high incidence of thromboembolic complications associated with diabetic ketoacidosis and the hyperosmolar syndrome, and the disturbances of the haemostatic system reported in this paper, controlled clinical trials of anticoagulant and antiplatelet drugs would appear to be justified in the management of these two conditions.

Acknowledgements. This work was supported by grant $75 / 569$ from the Medical Research Council. I thank Professor A. S. Douglas for help and encouragement throughout the study, and Professor J.M. Stowers and Dr. M. J. Williams for permission to study their patients.

\section{References}

1. Colwell JA (1980) Platelet function in diabetes mellitus. Br J Haematol 44: 521-526

2. Fuller JH, Keen H, Jarrett RJ, Omer T, Meade TW, Chakrabarti R, North WRS, Stirling Y (1979) Haemostatic variables associated with diabetes and its complications. Br Med J 2: $964-966$

3. Almer L-O, Nilsson IM (1975) On fibrinolysis in diabetes mellitus. Acta Med Scand 198: 101-106

4. Clements RS, Vourganti B (1978) Fatal diabetic ketoacidosis: major causes and approaches to their prevention. Diabetes Care 1: $314-325$

5. Whelton MJ, Walde D, Havard CWH (1971) Hyperosmolar non-ketotic diabetic coma: with particular reference to vascular complications. Br Med J 1: 85-86

6. Timperley WR, Preston FE, Ward JD (1974) Cerebral intravascular coagulation in diabetic ketoacidosis. Lancet 1 : 952-956

7. Kwaan HC, Colwell JA, Suwanwela N (1972) Disseminated intravascular coagulation in diabetes, with particular reference to the role of increased platelet aggregation. Diabetes 21: 108-113

8. Nicholson G, Tomkin GH (1974) Successful treatment of disseminated intravascular coagulopathy complicating diabetic coma. Br Med J 4: 450

9. Gordon EE, Kabadi VM (1976) The hyperglycaemic hyperosmolar syndrome. Am J Med Sci 271: 253-268

10. Brecher G, Cronkite EP (1950) Morphology and enumeration of blood platelets. J Appl Physiol 3: 365-377

11. Langdell RD, Wagner RH, Brinkhous KM, Hill C (1953) Effect of antihemophilic factor on one-stage clotting tests. A presumptive test for hemophilia and a simple one-stage antihemophilic factor assay procedure. J Lab Clin Med 41: 673-647

12. Quick AJ (1935) The prothrombin time in hemophilia and in obstructive jaundice. J Bio Chem 109: 73-74

13. Denson KWE (1966) Assay of factor V. In: Biggs R, MacFarlane RG (eds) Treatment of haemophilia and other coagulation disorders. Blackwell, Oxford, pp 368-369

14. Breckenridge RT, Ratnoff OD (1962) Studies on the nature of the circulatory anticoagulant directed against antihemophilic factor: with notes on an assay for antihemophilic factor. Blood 20: 137-149 
15. Bennett B, Ratnoff OD (1972) Studies on the response of patients with classical hemophilia to transfusion with concentrates of antihemophilic factor: a difference in the half-life of antihemophilic factor by procoagulant and immunologic technics. J Clin Invest 51: 2593-2596

16. Ogston CM, Ogston D (1966) Plasma fibrinogen and plasminogen in health and in ischaemic heart disease. J Clin Pathol 19: $352-356$

17. Alkjaersig N, Fletcher AP, Sherry S (1959) The mechanism of clot dissolution by plasmin. J Clin Invest 38: 1086-1095

18. Bennett NB, Ogston M, Ogston D (1967) Studies on the blood fibrinolytic enzyme system following acute myocardial infarction. Clin Sci 32: 27-37

19. Brozovic M (1977) Physiological mechanisms in coagulation and fibrinolysis. Br Med Bull 33: 231-236

20. Lufkin EG, Fass DN, O'Fallon WM, Bowie EJW (1979) Increased von Willebrand factor in diabetes mellitus. Metabolism 28: 63-66

21. Gensini GF, Abbate R, Favilla S, Neri Seneri GG (1979) Changes of platelet function and blood clotting in diabetes mellitus. Thromb Haemostas 42: 983-993

22. Gonzalez J, Colwell JA, Sarji KE, Nair RMG, Sagel J (1980) Effect of metabolic control with insulin on plasma von Willebrand factor activity (VIIIR:WF) in diabetes mellitus. Thromb Res 17: 261-266

23. Jaffe EA, Hoyer LW, Nachman RL (1973) Synthesis of antihemophilic factor antigen by cultured human endothelial cells. J Clin Invest 52: 2757-2764

24. Mustard JF, Packham MA (1977) Normal and abnormal haemostasis. Br Med Bull 33: 187-192
25. Davies JA, McNicol GP (1978) Blood coagulation in pathological thrombus formation and the detection in blood of a thrombotic tendency. Br Med Bull 34: 113-121

26. Denson KWE (1977) The ratio of factor VIII-related antigen and factor VIII biological activity as an index of hypercoagulability and intravascular clotting. Thromb Res 10: 107-119

27. Bick RL (1978) Disseminated intravascular coagulation and related syndromes: etiology, pathophysiology, diagnosis, and management. Am J Hematol 5: 265-282

28. Colman RW, Robboy SJ, Minna JD (1972) Disseminated intravascular coagulation (DIC): an approach. Am J Med 52: 679-689

29. Antoniades HN, Iatridis PG, Westmoreland N, Simon JD, Hayes HC, Surgenor DM (1973) Effects of nutritional, endocrine and metabolic state on the development of intravascular coagulation induced by human serum preparations with procoagulant activity. Thromb Diath Haemorrh 29: 33-49

Received: 17 November 1980

and in revised form: 22 May 1981

Dr. R. C. Paton

Department of Medicine

The Martin Wing

General Infirmary at Leeds

Great George Street

Leeds LSI $3 \mathrm{EX}$, UK 